\title{
O REGIME DE INTERNATO COMO ESTRATÉGIA DE EQUALIZAÇÃO DE OPORTUNIDADES AOS DISCENTES DO INSTITUTO FEDERAL DE EDUCAÇÃO, CIÊNCIA E TECNOLOGIA DO CEARÁ - CAMPUS CRATO
}

\author{
Maria Lucileide Costa Duarte ${ }^{1}$, Zósimo Mota Queiroz $^{1}$ \\ ${ }^{1}$ Instituto Federal de Educação, Ciência e Tecnologia do Ceará (IFCE) - Campus Crato \\ <lucileide@ifce.edu.br>, <zosimomqueiroz@hotmail.com>
}

DOI: 10.21439/conexoes.v10i1.784

\begin{abstract}
Resumo. Objeto de pesquisas e estudos de conceituados autores, a residência estudantil passou por mudanças que refletiram na sociedade. O Programa Nacional de Assistência Estudantil - PNAES, em suas ações, cita o direito à moradia. O Instituto Federal de Educação, Ciência e Tecnologia do Ceará campus Crato, desde sua gênese, tem o internato público masculino como fundamento de sua estrutura de ensino. No ano de 2008, através da Lei $\mathrm{n}^{\circ} 11.892$ de 30 de dezembro, as escolas agrotécnicas integraram os Institutos Federais de Educação, Ciência e Tecnologia, renovando a organização e gestão, sem excluir a oferta e objetivo do internato. Objetiva-se com esse estudo conhecer o regime de residência estudantil, sua eficácia como política de assistência estudantil e otimizar essa estrutura de assistência ao educando. Trata-se de uma pesquisa bibliográfica, permeando o internato como política de assistência estudantil, sua trajetória histórico-social e sua efetivação na Instituição aqui referenciada. A metodologia utilizada consistiu na leitura de livros, artigos, documentos oficiais, leis e decretos para conhecimento do assunto e posterior descrição. Conclui-se que, uma vez implantado o regime de internato, a instituição não deve ignorar a responsabilidade por ele advinda, pois a residência estudantil é um serviço que oferece assistência integral ao alunado, além de ser um recurso para a captação e permanência de estudantes provenientes de famílias em situação de vulnerabilidade.
\end{abstract}

Palavras-chaves: Internato. Residência Estudantil. Assistência Estudantil.

\begin{abstract}
The student housing has been an object of study and research of renowned authors and it underwent changes that had an impact in society. The National Student Assistance Program (PNAES) cites the right to housing. In Federal Institute for Education, Science and Technology of Ceará - campus Crato, male public boarding school has been the basis of the teaching structure since its foundation. Federal Law no 11,892, enacted on December 30 2008, allowed agro-technical schools to join the Federal Institutes for Education, Science and Technology, a decision that renewed organization and management of the housing schools, but did not affect their supply and purpose. The aim of this study is to understand the student housing scheme, its effectiveness as student assistance policy and optimize that structure. This is a literature search about student housing system as a policy of student assistance, its sociohistorical trajectory and its implementation in the Institution referenced here. The methodology consisted of reading books, articles, official documents, laws and decrees to knowledge and further description of the subject. It's concluded that, once the boarding school system is established, the institution must not ignore the responsibilities that are attached to it, because that service offers full assistance to students and it's a strategy to bring to the campus students whose families live in a vulnerable economic situation.
\end{abstract}

Keywords: Boarding schools. Student housing. Student Assistance. 


\section{INTRODUÇÃO}

As instituições educacionais possuidoras de regime de internato, ofertando residências aos seus discentes, encontram-se como alvo de estudos há séculos. Foco de pesquisas e estudos de autores renomados, o internato sofreu transformações que atingiram, entre outros, aspectos da vida social, educacional e familiar.

No Brasil, oferecer residências a alunos de cursos profissionalizantes e técnicos consistia em estratégia para capacitar a camada da sociedade mais desguarnecida economicamente, tendo como finalidade a utilização desta como mão-de-obra no processo de industrialização existente no século XX. Com a evolução histórica e social, o regime de internato passou a tornar-se fundamental ao combate da evasão escolar e a fomentar a igualdade de oportunidades para alunos da rede pública de ensino.

Neste estudo, faremos considerações sobre o desenrolar histórico da educação técnica federal no Brasil, permeando o Programa Nacional de Assistência Estudantil, conceituando o regime de internato e contextualizando com a realidade do Instituto Federal de Educação, Ciência e Tecnologia do Ceará - Campus Crato, hoje instituição adotante do regime de internato. Por fim, apoiando-nos no estudo bibliográfico apresentado durante a pesquisa e em nossa experiência profissional, exibiremos as conclusões do estudo no intuito de contribuir para o debate sobre a eficácia atual do regime de internato nas instituições de ensino e, tratando-se de educação pública, de sua função de equalizar oportunidades para indivíduos advindos de camadas sociais e econômicas distintas.

\section{FUNDAMENTAÇÃO TEÓRICA}

\subsection{Evolução Histórica da Educação Técnica Fede- ral}

Resgatando um pouco a história no que se refere à educação profissional, o cenário socioeconômico no período correspondente à primeira República revelou uma intensificação do processo de urbanização e industrialização, o que fez emergir um novo modelo de sociedade. Esta, passando de escravista para assalariada, começou a exigir qualificação profissional adequada ao perfil de produção que iniciava. Nesse período, o então presidente Nilo Peçanha assina, em 23 de setembro de 1909, o Decreto 7.566, criando 19 Escolas de Aprendizes Artífices destinadas ao ensino profissional primário e gratuito. Dessa forma, considerou-se a necessidade de habilitar os desfavorecidos, levando-os ao preparo técnico e intelectual, bem como afastando-os da ociosidade, dos vícios e crimes (FEITOSA, 2010).
Ressaltamos que o ensino técnico profissional e industrial foi tratado especificamente na Constituição Brasileira de 1937, onde faz referência ao ensino prévocacional e profissional para as classes menos favorecidas e responsabiliza as indústrias e sindicatos econômicos a criarem escolas de aprendizes para os filhos de seus operários ou de seus associados. Esse contexto possibilitou a definição das Leis Orgânicas do Ensino Profissional e a criação do Serviço Nacional de Aprendizagem Industrial - SENAI, em 1942, o Serviço Nacional de Comércio - SENAC, em 1946, e a transformação das Escolas de Aprendizes e Artífices em Escolas Industriais e Técnicas, em 1942, oferecendo formação profissional em nível equivalente ao do secundário (CAMPOS, 2005, BRASIL, 2013).

Nos anos do governo do presidente Juscelino Kubitschek (1956-1961) o processo de industrialização nacional do país consolidou-se e, ao mesmo tempo, intensificou-se a formação de técnicos, mão-de-obra indispensável diante do crescimento industrial. No ano de 1959 as Escolas Industriais e Técnicas são transformadas em Escolas Técnicas Federais. Em 1978 as do Rio de Janeiro, Minas Gerais e Paraná transformaram-se em Centros Federais de Educação, Ciência e Tecnologia CEFETs. Em 30 de dezembro de 2008, por meio da Lei 11.892, os CEFETs, as Escolas Técnicas e Agrotécnicas Federais e as Escolas Técnicas vinculadas às Universidades Federais se transformaram em Institutos Federais de Educação, Ciência e Tecnologia - IFs. Esses Institutos fazem parte da política de expansão da rede federal de educação profissional, que teve início em 2003 e perdurou nos governos do presidente Lula da Silva (OTRANTO, 2011).

Em alusão aos Institutos Federais, Pacheco (2011) menciona:

\footnotetext{
Os Institutos Federais de Educação, Ciência e Tecnologia são a síntese daquilo que de melhor a Rede Federal construiu ao longo de sua história e das políticas de educação profissional e tecnológica do governo federal. São caracterizados pela ousadia e inovação necessárias a uma política e a um conceito que pretendem antecipar aqui e agora as bases de uma escola contemporânea do futuro e comprometida com uma sociedade radicalmente democrática e socialmente justa. (PACHECO 2011 p. 12)
}

Expressando seu pensamento a respeito dos IFs, Otranto (2011) chama a atenção de sua estrutura diferenciada.

\footnotetext{
Os Institutos Federais devem constituir-se como centros de excelência na oferta de ensino das ciências, em geral, e de ciências aplicadas, em particular [...] Os IFs sintetizam, hoje, a expressão maior da atual política pública
} 
O REGIME DE INTERNATO COMO ESTRATÉGIA DE EQUALIZAÇÃO DE OPORTUNIDADES AOS DISCENTES DO INSTITUTO FEDERAL DE EDUCAÇÃO, CIÊNCIA E TECNOLOGIA DO CEARÁ - CAMPUS CRATO

\begin{abstract}
de educação profissional brasileira, e estão produzindo mudanças significativas na vida e na história das instituições que optaram por aderir à proposta governamental (OTRANTO 2011 p. 11-12).
\end{abstract}

Assim, a história da educação pública, enquanto demanda social, está associada à luta pela construção dos direitos sociais e humanos, consubstanciada essa trajetória na luta pela construção do Estado de Direito ou Estado Social. A democratização da educação não está limitada apenas ao acesso à instituição educativa, precisa-se garantir que todos os que ingressem na escola tenham condições de permanência (CONAE, 2010).

Com esse intuito, o Programa Nacional de Assistência Estudantil - PNAES foi instituído no âmbito da Secretaria do Ministério de Educação Superior - SESu, do Ministério de Educação, por meio da Portaria Normativa $\mathrm{n}^{\mathrm{o}} 39$ de 12 de dezembro de 2007 . Este programa tem a finalidade de ampliar as condições de permanência dos jovens na educação superior pública federal, abrangendo também os Institutos Federais de Educação, Ciência e Tecnologia. Suas ações devem ser desenvolvidas nas áreas de moradia estudantil, alimentação, transporte, atenção à saúde, inclusão digital, cultura, esporte, creche, apoio pedagógico e acesso, participação e aprendizagem de estudantes com deficiência, transtornos globais de desenvolvimento e altas habilidades e superdotação (BRASIL, 2010).

Em seguida, faremos breve descrição do Programa Nacional de Assistência Estudantil, como também da caracterização do regime de internato. Depois daremos algumas informações sobre nossa experiência profissional no IFCE Campus Crato.

\subsection{O Programa de Assistência Estudantil}

A trajetória histórica da Assistência Estudantil bem como seu surgimento no Brasil vincula-se à trajetória da política de assistência social, frisando o fato de o surgimento de ambas ter sido a partir dos movimentos sociais que lutaram pelo fim do regime militar (19641985) e pela promulgação da Constituição Federal de 1988. Nesse período, surgiram duas frentes políticas sobre as questões educacionais, sobretudo em alusão às questões relativas à assistência estudantil, que culminaram no Fórum Nacional de Pró-Reitores de Assuntos Comunitários e Estudantis - FONAPRACE e a Associação Nacional de Dirigentes das Instituições Federais de Ensino Superior - ANDIFES, no ano de 1987. De acordo com Vasconcelos (2010):

Esses dois segmentos educacionais defendiam a integração regional e nacional das instituições do ensino superior com o objetivo de: garantir a igualdade de oportuni-

\begin{abstract}
dades aos estudantes das Instituições Federais de Ensino Superior (IFES) na perspectiva do direito social, além de proporcionar aos alunos as condições básicas para sua permanência e conclusão do curso, contribuindo e prevenindo a erradicação e retenção e a evasão escolar decorrentes das dificuldades socioeconômicas dos alunos de baixa renda. (VASCONCELOS 2010, p. 604).
\end{abstract}

Em 1988 foi promulgada a Constituição Federal que representou um marco histórico no que alude às questões referentes à inclusão dos direitos políticos e sociais dos cidadãos. No que se refere à Educação tem-se no capítulo III - seção I - art. 205:

\footnotetext{
A Educação, direito de todos e dever do estado e da família, será promovida e incentivada com a colaboração da sociedade, visando ao pleno desenvolvimento da pessoa, seu preparo para o exercício da cidadania e sua qualificação para o trabalho. (BRASIL, 1988).
}

$\mathrm{O}$ art. $206^{\circ}$ da Carta Magna preconiza que o ensino será ministrado com base em princípios, sendo um deles, o inciso I - igualdade de condições para o acesso e permanência na escola. Com relação à Assistência Social, o capítulo VIII, art. 203 determina que "a assistência social será prestada a quem dela necessitar, independentemente de contribuição à seguridade social..."(BRASIL, 1988).

\section{Para YASBEK:}

... as políticas sociais assumem papel de atenuar, através dos programas sociais, os desequilíbrios no usufruto da riqueza social entre as diferentes classes sociais decorrentes das precárias condições de vida a que se encontram submetidas as classes subalternas. (YASBEK 2003 p. 41).

Pela primeira vez na história dos direitos sociais, a constituição considera a assistência social como política social, pois:

Desde a era medieval e avançando para épocas mais recentes, que atingiram até mesmo o século XIX, a assistência era encarada como forma de controlar a pobreza e de ratificar a sujeição daqueles que não detinham posses ou bens materiais. Assim, seja na assistência prestada pela burguesia, seja naquela realizada pelas instituições religiosas, havia sempre intenções outras, além da prática da caridade, ratificar a submissão. (MARTINELLI 2003 p. 97).

A partir da nova compreensão sobre Educação e Assistência, iniciou-se um período de reflexões e mudanças, inaugurando o padrão de proteção social afirmativo de direitos e superando as práticas assistencialistas 
O REGIME DE INTERNATO COMO ESTRATÉGIA DE EQUALIZAÇÃO DE OPORTUNIDADES AOS DISCENTES DO INSTITUTO FEDERAL DE EDUCAÇÃO, CIÊNCIA E TECNOLOGIA DO CEARÁ - CAMPUS CRATO

e clientelistas. Em 20 de dezembro de 1996 foi aprovada a Lei de Diretrizes e Bases da Educação que contém dispositivos que amparam a assistência estudantil, entre os quais se destaca: Art. $3^{\circ}$ - o ensino será ministrado com base nos seguintes princípios: I- igualdade de condições para o acesso e permanência na escola... O Decreto 6.096, de 24 de abril de 2007, que institui o Programa de Apoio ao Plano de Reestruturação e Expansão das Universidades Federais (REUNI), em seu art. $1^{\mathrm{o}}$ preconiza:

Fica instituído o Programa de Apoio a Planos de Reestruturação e Expansão das Universidades Federais REUNI, com o objetivo de criar condições para a ampliação do acesso e permanência na educação superior, no nível de graduação, pelo melhor aproveitamento da estrutura física e de recursos humanos existentes nas universidades federais. (BRASIL, 2007).

E em seu art. $2^{\circ}$, aponta como diretriz do Programa a "ampliação de políticas de inclusão e assistência estudantil"(BRASIL, 2007).

Nesse contexto, faz-se mister destacar, como já dissemos, a criação do PNAES, que foi promulgado em 12 de dezembro de 2007, por meio da Portaria Normativa no 39 do Ministério da Educação, instituído no âmbito da Secretaria de Educação Superior - SESu, e consolidado como Programa de Estado, instituído pelo MEC, somente em 19 de julho de 2010, através do Decreto $\mathrm{n}^{\circ}$ 7.234 da Presidência da República.

Andrés (2011) lembra que a implantação dos programas REUNI (Programa de Reestruturação e Expansão das Universidades), Programa de Expansão da Rede Federal de Educação Profissional e Tecnológica, PROUNI (Programa Universidade Para Todos), a nova versão do FIES (Financiamento Estudantil) e as metas do $2^{\circ}$ Plano de Educação (PNE 2011-2020) trouxeram concomitantemente um problema grave: parte significativa do novo alunado não poderia ao mesmo tempo estudar e trabalhar e não dispunha de recursos para pagar a alimentação, moradia, material didático, transporte e outros itens fundamentais à vida estudantil, o que acabaria por levar ao abandono dos estudos. Neste contexto, argumenta-se que o PNAES é uma ferramenta indispensável para a garantia da assistência estudantil enquanto um direito social voltado à igualdade de oportunidades aos estudantes do ensino superior. Nessa linha de raciocínio, Vasconcelos 2010) menciona:

A assistência estudantil, enquanto mecanismo de direito social, tem como finalidade prover os recursos necessários para transposição dos obstáculos e superação dos impedimentos do bom desempenho acadêmico permitindo que o estudante desenvolva-se perfeitamente bem durante a graduação e obtenha um bom desempenho curricular minimizando, dessa forma, o percentual de abandono, de trancamento de matrícula (VASCONCELOS. 2010 p. 609).

Conforme mencionado anteriormente, o PNAES faz referência, dentre suas ações, ao direito à moradia. $\mathrm{O}$ estudante pode ser contemplado com o recebimento do auxílio-moradia ou ser inserido no serviço de moradia ofertado pela instituição. Dessa forma, discorreremos a seguir sobre o Internato.

\subsection{Regime de Internato}

As Instituições que ofertam o internato como alternativa de permanência do estudante na escola, adotam o conceito de espaço onde os discentes vivem com seus pares em residências destinadas à moradia, proporcionandolhes o direito de permanecer durante os dias de aula e, quando necessário, finais de semana e feriados.

Visitando a obra de Ariès (1986), encontramos algumas notificações acerca do internato no decorrer dos séculos XV a XVII. Há um relato de que os alunos eram abandonados a si mesmos e alvo de grande controle:

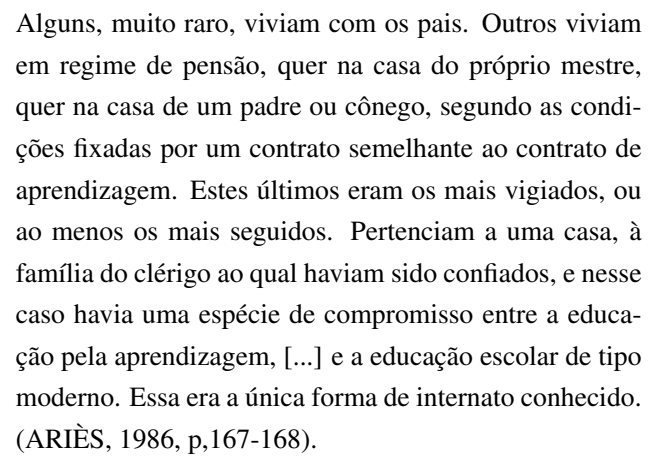

O autor também faz referência à disciplina como o diferencial entre a escola da idade média e o colégio dos tempos modernos:

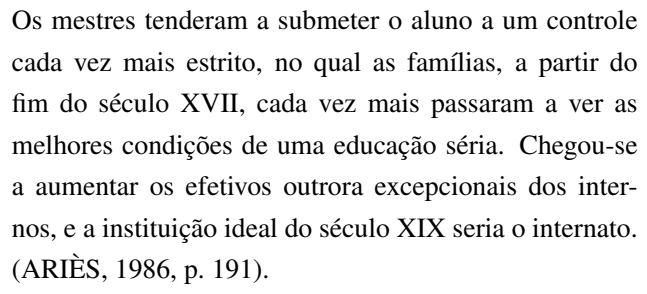

Em se tratando do termo disciplina, Foucault (2009) aponta que o poder disciplinar tem como função maior o "adestramento", seja do corpo e/ou da mente.

\footnotetext{
'Adestra' as multidões confusas, móveis, inúteis células separadas, autonomias orgânicas, identidades e continuidades genéticas, segmentos combinatórios. A disciplina
} 
O REGIME DE INTERNATO COMO ESTRATÉGIA DE EQUALIZAÇÃO DE OPORTUNIDADES AOS DISCENTES DO INSTITUTO FEDERAL DE EDUCAÇÃO, CIÊNCIA E TECNOLOGIA DO CEARÁ - CAMPUS CRATO

\begin{abstract}
'fabrica' indivíduos; ela é a técnica específica de um poder que toma os indivíduos ao mesmo tempo como objetos e como instrumentos de seu exercício. (FOUCAULT) 2009 p. 164).
\end{abstract}

O mesmo autor, quando se refere à arte das distribuições em sua obra, menciona que a disciplina procede à distribuição dos sujeitos no espaço e, para isso, utilizava diversas técnicas. Fazendo referência aos colégios, expressa: "o modelo do convento se impõe pouco a pouco; o internato aparece como o regime de educação, se não o mais frequente, pelo menos o mais perfeito [...]"(FOUCAULT, 2009, p. 137).

No tocante ao internato, Goffman (2008) compreende que a instituição total é imprescindível para o entendimento do regime de internato. Em sua concepção, trata-se de:

[...] um local de residência e trabalho onde um grande número de indivíduos com situação semelhantes, separados da sociedade mais ampla por considerável período de tempo, levam uma vida fechada e formalmente administrada [...] um híbrido social, parcialmente comunidade residencial, parcialmente organização formal [...] são as estufas para mudar pessoas, cada uma é um experimento natural sobre o que se pode fazer ao eu. GOFFMAN 2008 p. $11-22$ ).

Ainda sobre esse assunto, o autor apresenta características que revestem a instituição total, tais como: a totalidade, isto é, todos os aspectos da vida são realizados no mesmo espaço e sob a única autoridade; a segregação, uma vez que no interior do internato há divisão básica entre o grupo que controla e outro que é controlado; atividades coletivas e iguais para todo o grupo e a normalização, isto é, a existência do plano único para atender aos objetivos oficiais da instituição. (GOFFMAN, 2008, p. 17-18).

Ao falarmos de internato escolar agrícola, as instituições federais de ensino profissional do Brasil desenvolveram-no durante o período de 1934 a 1967, tendo como responsável o Ministério da Agricultura. Aos internos se ofertava a política assistencial integral que possibilitava a viabilização de seus estudos. Em 1967, ocorreu a reforma administrativa dos Ministérios e o ensino agrícola foi absorvido pelo Ministério da Educação e Cultura. Ao assumir o ensino agrícola, através da Diretoria de Ensino Agrícola-DEA, implantouse a metodologia do sistema escola-fazenda que se baseou no princípio "aprender a fazer e fazer para aprender". (SOBRAL, 2009).

No ano de 2008, através da Lei ${ }^{0} 11.892$ de 30 de dezembro, as escolas agrotécnicas foram transformadas em Institutos Federais de Educação, Ciência e Tecnologia, iniciando a nova organização e gestão, sem excluir a oferta e o objetivo do internato.

\subsection{Instituto Federal de Educação, Ciência e Tec- nologia do Ceará- Campus Crato}

Tomando como referência o Plano de Desenvolvimento Institucional 2014-2018, a origem do Instituto Federal de Educação, Ciência e Tecnologia do Ceará - Campus Crato emerge no termo celebrado entre o Governo da União e a Prefeitura Municipal do Crato para a instalação da Escola Agrotécnica, em conformidade com os artigos $2^{\circ}$ e $4^{\circ}$ do Decreto Federal $n^{\circ} 22.470$, de 20 de janeiro de 1947, instalando o Ensino Agrícola no Brasil e os dispositivos do Decreto-Lei $n^{\circ}$ 9.613, de 20 de agosto de 1946. Em 10 de abril de 1954 foi assinado o termo de instalação da Escola Agrotécnica do Crato, vinculada à Superintendência do Ensino Agrícola e Veterinário - SEAVE, do Ministério da Agricultura. As atividades iniciaram-se com a implantação do curso de Tratorista.

Desse período até o ano de 2009, quando se tornou campus do IFCE, diversas reestruturações políticoadministrativas do Governo Federal provocaram mudanças nas vinculações desta Escola às Secretarias dos Ministérios. Pelo Decreto 60.731, de 19 de maio de 1967, o Colégio Agrícola de Crato foi transferido do Ministério da Agricultura para o Ministério da Educação e Cultura. A SEAVE, por sua vez, foi transformada em Diretoria do Ensino Médio.

Ao longo desses anos, esta Escola esteve vinculada a diversas secretarias do Ministério da Educação que nasceram e se extinguiram por razões administrativas. Esteve vinculada à Coordenação Nacional de Ensino Agrícola, à Coordenação Nacional de Ensino Agropecuário, à Secretaria de Ensino de $2^{\circ} \mathrm{Grau}$ e, atualmente, por ser Campus do IFCE, está vinculada à Secretaria de Educação Profissional e Tecnológica (SETEC). As denominações desta unidade também passaram por alterações. Originou-se com o nome de Escola Agrotécnica do Crato, depois, pelo Decreto 53.558, de 13 de fevereiro de 1964, mudou para Colégio Agrícola do Crato. Em seguida, pelo Decreto 83.935, de 04 de setembro de 1979, passou a denominar-se Escola Agrotécnica Federal de Crato, última denominação antes de transformarse em Campus do IFCE, no ano de 2009 (IFCE, 2013. p. 12).

O IFCE Campus Crato oferta o Ensino Profissional Técnico de Nível Médio, através dos cursos: Técnico em Agropecuária Integrado ao Ensino Médio, Técnico em Agropecuária pós-médio (subsequente) e Técnico em Informática para Internet Integrado ao Ensino Mé- 
O REGIME DE INTERNATO COMO ESTRATÉGIA DE EQUALIZAÇÃO DE OPORTUNIDADES AOS DISCENTES DO INSTITUTO FEDERAL DE EDUCAÇÃO, CIÊNCIA E TECNOLOGIA DO CEARÁ - CAMPUS CRATO

dio. Além desses, oferece também a Educação de Jovens e Adultos na modalidade PROEJA - Técnico em Informática para Internet. Quanto ao Ensino Superior, existem os cursos bacharelados: Sistemas de Informações e Zootecnia.

Sobre o tipo de regime escolar, o Campus Crato oferece três alternativas para os estudantes. São elas: a residência estudantil para os alunos de sexo masculino, em que o discente permanece na instituição durante a semana e, se quiser, nos finais de semana e feriados; a semirresidência, que oportuniza o discente a passar dois turnos na instituição, com direito à refeição, e o regime externo em que o discente deixa de permanecer no espaço estudantil após o turno de aula.

Vale ressaltar que a residência estudantil consiste em elemento atrativo para os estudantes provenientes de famílias de condição econômica desfavorável, de municípios distantes ou circunvizinhos da sede do campus. Além disso, esse serviço presta uma assistência integral aos estudantes, visto que dispõem de moradia e refeições gratuitas de boa qualidade, além de outros serviços prestados pela equipe de assistência estudantil da instituição.

\section{CONSIDERAÇÕES FINAIS}

Após esse estudo sobre o ensino técnico no Brasil, a análise de sua política de assistência estudantil, consulta do conceito e reflexão sobre o regime de internato e contextualização com a realidade do Instituto Federal de Educação, Ciência e Tecnologia do Ceará - Campus Crato, torna-se imperioso pesquisar com mais profundidade o regime de residência. Não restam dúvidas sobre a importância de oferecer o serviço de moradia à parcela significativa de alunos domiciliados em regiões distantes. Mediante essa colocação, poderíamos chegar a uma indagação: Qual a eficácia do internato como política de assistência estudantil aplicada aos discentes do Instituto Federal de Educação, Ciência e Tecnologia do Ceará - Campus Crato?

Embora trate-se de regime antigo, o internato, com sua evolução, ainda apresenta-se como uma estratégia eficaz para educar. Por meio do regime de residência estudantil, a instituição proporciona ao discente a oportunidade de estudar, mesmo distante de sua cidade. Isso se torna necessário quando a instituição oferta um curso não existente na localidade onde o aluno e sua família se encontram, caso recorrente nos cursos técnicos integrados ao ensino médio.

$\mathrm{O}$ regime de internato pode, em alguns casos, ser substituído por outras políticas de assistência estudantil. Podemos exemplificar, apenas para citar, pois sem dúvidas tornar-se-á foco de pesquisas futuras, o caso dos alunos do ensino superior. Estes, em sua maioria, são pessoas adultas que necessitariam mais de ajuda financeira para aluguel e transporte que propriamente de acompanhamento pedagógico institucional.

Isso não se aplica, por sua vez, ao alunado que precisa ausentar-se de sua cidade de origem e distanciar-se de sua família para fazer o ensino médio integrado a algum curso técnico profissionalizante. Esses estudantes, segundo o Estatuto da Criança e do Adolescente, consistem em pessoas em desenvolvimento. Por esse motivo o acompanhamento pedagógico torna-se prioritário, juntamente com a oferta de moradia e demais condições de permanência na instituição que escolheram para cursar seu ensino médio integrado.

Adotando-se o regime de internato, a instituição não pode ignorar a responsabilidade que isto implica. As futuras pesquisas, entre outras prioridades, devem focar no desempenho dos discentes beneficiados com as residências estudantis e na estrutura necessária ao regime de internato para que seus contemplados possam gozar de desenvolvimento físico, mental, moral, espiritual e social, como preceitua a legislação vigente.

\section{REFERÊNCIAS}

ANDRÉS, A. Aspectos da Assistência Estudantil nas Universidades Brasileiras. Consultoria Legislativa da Área XV Educação e Cultura. Brasília: [s.n.], 2011. Biblioteca Digital da Câmara dos Deputados. Centro de Documentação e Informação. Disponível em: <http:// www.bd.camara.gov.br/bd/bitstream/handle/bdcamara/ 7284/aspects_assistencia_andres.pdf?sequence $=3>$ Acesso em: 25 dez. 2012.

ARIÈS, P. História social da criança e da família. 2. ed. Rio de Janeiro: Guanabara, 1986. Tradução Dora Flaksman.

BRASIL. Constituição(1988). Constituição da República Federativa do Brasil: promulgada em 5 de outubro de 1988. 1988. Disponível em: <www.senado.gov.br/legislacao/const/con1988/ con1988_05.10.1988/con1988.pdf>. Acesso em: 25 dez. 2012.

Decreto $n^{\circ}$ 6.096, de 24 de abril de 2007. Institui o Programa de Apoio a Planos de Reestruturação e Expansão das Universidades Federais - REUNI. 2007. Disponível em: <http://www.planalto.gov.br/ccivil_03/ _ato2007-2010/2007/decreto/d6096.htm> Acesso em: 24 out. 2012 .

Decreto $n^{\circ} 7.234$ de 19 de julho de 2010. Dispõe sobre o Programa Nacional de Assistência Estudantil- 
O REGIME DE INTERNATO COMO ESTRATÉGIA DE EQUALIZAÇÃO DE OPORTUNIDADES AOS DISCENTES DO INSTITUTO FEDERAL DE EDUCAÇÃO, CIÊNCIA E TECNOLOGIA DO CEARÁ - CAMPUS CRATO

PNAES. 2010. Disponível em: <http//gest ao2010. mec.gov.br/marcos_legais/decree_36.php $>$. Acesso em: 25 dez. 2012.

. Ministério da Educação. Centenário da Rede Federal de Educação Profissional e Tecnológica. 2013. Disponível em: <http: //portal.mec.gov.br/index.php?option=com_content\& view $=$ article\&id13175.Acesso $>$ Acesso em: 23 jan. 2013.

CAMPOS, J. d. O. Análise comparativa dos modelos curriculares de educação profissional agrícola: sistema escola-fazenda e formação por competência no CEFET de Urutaí/GO. Dissertação (Mestrado em Educação Agrícola) — Programa de Pós-Graduação em Educação Agrícola, Universidade Federal Rural do Rio de Janeiro, Seropédica, 2005.

CONAE. Construindo o Sistema Nacional Articulado de Educação: O Plano Nacional de Educação, Diretrizes e Estratégias de Ação. Documento referência. Brasília: [s.n.], 2010. Disponível em: $<$ portal.mec.gov.br/dmdocuments/cadfinal_educ_ integral.pdf>. Acesso em: 25 dez. 2012.

FEITOSA, T. d. S. As "reformas"do ensino profissionalizante de 1996 a 2006 na Escola Agrotécnica Federal de Crato Ceará: acomodação à legislação ou consciência da prática? Dissertação (Mestrado em Educação Agrícola) — Programa de Pós-Graduação em Educação Agrícola, Universidade Federal Rural do Rio de Janeiro, Seropédica, 2010.

FOUCAULT, M. Vigiar e punir: nascimento da prisão. 37. ed. Petrópolis: Vozes, 2009. Tradução de Raquel Ramalhete.

GOFFMAN, E. Manicômios, prisões e conventos. São Paulo: Perspectiva, 2008. 312p.

IFCE. PLANO DE DESENVOLVIMENTO INSTITUCIONAL 2014-2018. Crato, 2013. P.12.

MARTINELLI, M. L. Serviço Social: identidade e alienação. 8. ed. São Paulo: Cortez, 2003. 165p.

OTRANTO, C. R. A Política de Educação Profissional do Governo Lula: novos caminhos da educação superior In: $34^{a}$ REUNIÃO ANUAL DA ANPED-NATAL, RN. 2011. Disponível em: $<$ http://34reuniao.anped.org.br/images/trabalhos/ GT11/GT-315\%20int.pdf> Acesso em: 13 fev. 2013.

PACHECO, E. Institutos Federais: uma revolução na educação profissional e tecnológica. São Paulo: Moderna, 2011.
SOBRAL, F. J. M. Retrospectiva histórica do ensino agrícola no brasil. Revista Brasileira da Educação Profissional e Tecnológica, v. 2, n. 2, p. 78 - 95, 2009.

VASCONCELOS, N. B. Programa nacional de assistência estudantil: Uma análise da evolução da assistência estudantil ao longo da história da evolução da educação superior no brasil. Ensino Em-Revista, v. 17 , n. 2, p. $599-616,2010$.

YASBEK, M. C. Classes subalternas e assistência social. 4. ed. São Paulo: Cortez, 2003. 184p. 